\title{
Systematic Review: Non-medical Switching of Infliximab to CT-P13 in Inflammatory Bowel Disease
}

\author{
Edmond-Jean Bernard ${ }^{1} \cdot$ Richard N. Fedorak ${ }^{2} \cdot$ Vipul Jairath $^{3}$
}

Received: 9 April 2019 / Accepted: 28 December 2019 / Published online: 22 January 2020

(C) The Author(s) 2020

\begin{abstract}
Background and Aims Biosimilar approval, such as Inflectra ${ }^{\mathrm{TM}}$ (CT-P13) for treating ulcerative colitis (UC) and Crohn's disease (CD), has reduced direct drug costs. Though clinicians are comfortable with biosimilar use in treatment-naïve patients, there are concerns in some jurisdictions that there are insufficient data from well-controlled trials to support non-medical switching. A systematic review, along with a critical assessment of the study design, was conducted to assess the potential impact of switching stable CD/UC patients from infliximab to CT-P13.

Methods A literature search using PubMed and abstracts/posters from 3 major gastroenterology conferences from 2014 to 2018 was completed. Two individual reviewers extracted data from each relevant report and compiled it into evidence tables to facilitate descriptive analyses. Key randomized trial and observational study designs were critically assessed to contextualize data relevance.

Results A total of 49 reports ( 3 randomized controlled trials, 40 observational trials, and 1 case series) were included. Most studies revealed no efficacy, safety, or immunogenicity concerns with non-medical switch. Limitations of supporting data include a small number of randomized controlled trials; predominance of observational studies with varying outcome assessments and lack of appropriate controls; and scarcity of research on biosimilar switch long-term effects.

Conclusions The majority of studies suggested non-medical switch is safe. However, clinicians and regulatory bodies should be aware of differences and limitations in study designs when making inferences about the risks and benefits of switching stable IBD patients to biosimilars.
\end{abstract}

Keywords Inflammatory bowel disease $\cdot$ Ulcerative colitis $\cdot$ Crohn's disease $\cdot$ Infliximab $\cdot$ CT-P13 $\cdot$ Biosimilar

Vipul Jairath

vjairath@uwo.ca

Edmond-Jean Bernard

ejb.ibd@gmail.com

Richard N. Fedorak

richard.fedorak@ualberta.ca

1 CHUM, Université de Montréal, 1051 Rue Sanguinet, Montréal, QC H2X 3E4, Canada

2 Faculty of Medicine and Dentistry, University of Alberta, 8440112 St. NW, Edmonton, AB T6G 2R7, Canada

3 Epidemiology and Biostatistics, Division of Gastroenterology, London Health Sciences Centre, Western University, 339 Windermere Rd, London, ON N6A 5A5, Canada

\section{Introduction}

The introduction of biologic therapies approximately 20 years ago resulted in unparalleled benefits for the treatment of chronic immune-mediated inflammatory diseases (IMIDs), such as rheumatoid arthritis (RA) and inflammatory bowel disease (IBD). Biologic drugs are complex macromolecules produced from living cells that are genetically modified for commercial-scale production and are estimated to account for approximately $32 \%$ of global pharmaceutical sales by 2023 [1]. Remicade ${ }^{\circledR}$ (infliximab) was the first biologic (an originator biologic) on the market for IBD. It is a murine chimeric anti-tumor necrosis factor $\alpha(\mathrm{TNF} \alpha)$ monoclonal antibody used for the treatment of RA, ankylosing spondylitis (AS), plaque psoriasis ( $\mathrm{PsO}$ ), psoriatic arthritis (PsA), ulcerative colitis (UC), and Crohn's disease (CD) [2]. In 2016, global Remicade sales reached almost $\$ 8$ billion (USD) [3]. In addition to market share growth, infliximab 
has been increasingly used for IBD treatment to prevent UC and $\mathrm{CD}$ progression in some countries [4-7].

Over the past 5 years, a number of biosimilars have been approved for use by Health Canada. Biosimilars are biologic therapies that are highly similar, but not identical, to their respective originator biologic products. Although biosimilarity does not require all aspects of the biosimilar and originator products to be the same, biosimilars go through a rigorous comparative pre-approval testing process, where data demonstrating similarity between the originator and biosimilar must be provided [8]. As such, the type of data to support biosimilars is different than for a stand-alone biologic, and these attenuated clinical trial requirements mean that biosimilars can be offered at a lower price point versus originator molecules. Biologic therapies are complex, microheterogeneous molecules that are highly sensitive to changes in both raw materials and manufacturing conditions. Therefore, small differences exist between biosimilars and their originator products, which may lead to differences in efficacy, safety, or immunogenicity [8].

CT-P13 (marketed as Inflectra ${ }^{\circledR}$ in Canada and Remsima $^{\mathrm{TM}}$ elsewhere) is the first infliximab biosimilar approved in Canada for similar indications as Remicade ${ }^{\circledR}$, except for pediatric UC and CD, based on clinical trials in AS and RA. The availability of this lower-cost alternative may prompt payors to adopt strategies that prioritize biosimilars preferentially over innovator use to reduce healthcare expenditures [9]. In several countries, non-medical switch from an originator molecule to its biosimilar has emerged as a treatment strategy, typically driven by economic or access reasons. While the safety and efficacy of biosimilar use in infliximabnaïve patients is generally accepted, a "forced switch" to save costs concerns some gastroenterologists, who cite a lack of high-quality controlled trials to support such decisions in stable patients. The objective of this systematic review was to examine the current literature on biosimilar switch and its implications for guiding treatment decisions. To that end, we conducted a systematic review of studies in which patients with CD or UC were switched from infliximab to CT-P13 and reviewed the potential impact on efficacy, response, and safety. The study designs of key randomized clinical trials and observational studies were also critically assessed to contextualize the relevance of the available data.

\section{Materials and Methods}

The systematic review search strategy was developed to examine the following participants, interventions, comparisons, and outcomes (PICO) items: (P) randomized controlled trials and observational studies of patients diagnosed with CD or UC who were switched to (I) CT-P13 from (C) infliximab and the effect of non-medical switch on $(\mathrm{O})$ efficacy/effectiveness, response, and safety as inferred from disease worsening, loss of response, and sustained remission rate data. This systematic review was not registered with PROSPERO. This systematic review is in accordance with the PRISMA checklist (Table 1).

\section{Search Methods}

A systematic review of the PubMed database was completed in April 2018, using the terms "(((switch OR switching OR interchange OR interchanged [All Fields])) AND infliximab [All Fields]) AND (ulcerative colitis OR inflammatory bowel disease OR Crohn[MeSH Terms])" with no date restrictions, filtered by text availability (only full-text publications were included). Abstracts from the Congress of European Crohn's and Colitis Organization (ECCO, 2013-2018) and Digestive Disease Week (DDW, 2013-2017) via the journal Gastroenterology were searched using the terms "infliximab AND biosimilar AND (inflammatory OR IBD)" and "infliximab AND biosimilar." The absence of a searchable database for United European Gastroenterology Week (UEGW, 2013-2017) required oral and poster abstracts, in portable document format, to be scanned using the term "infliximab."

\section{Selection Criteria}

Titles and abstracts were identified as potentially eligible by two independent individuals. Studies were eligible if they included data on patients with CD or UC treated with infliximab originator who were stable at the time of switch to CT-P13 and were written in the English language. Appropriate conference abstracts were analyzed to minimize publication bias. UEGW abstracts that included the term "infliximab" were further screened for eligibility criteria, as mentioned above. Review articles, meta-analyses, and other non-clinical papers were excluded. Two individuals then independently examined the full text of the remaining publications and conference abstracts deemed to match the eligibility criteria, with data extracted in duplicate. Any discrepancies were resolved by discussion.

\section{Data Extraction}

Data were extracted from each relevant report. Each publication was individually reviewed to identify data concerning: study information — primary author, year of publication, title of publication, type of study (randomized or observational); patient characteristics - total number of patients, number of included patients with CD or UC; and study data-interventions, duration of follow-up, efficacy outcomes (disease worsening, loss of response, and sustained remission rates), discontinuation rate, immunogenicity, and safety (adverse 
Table 1 PRISMA checklist

\begin{tabular}{|c|c|c|}
\hline Section/topic & \# & Checklist item \\
\hline \multicolumn{3}{|l|}{ Title } \\
\hline Title & 1 & Identify the report as a systematic review, meta-analysis, or both \\
\hline \multicolumn{3}{|l|}{ Abstract } \\
\hline Structured summary & 2 & $\begin{array}{l}\text { Provide a structured summary including, as applicable: background; objectives; data sources; } \\
\text { study eligibility criteria, participants, and interventions; study appraisal and synthesis methods; } \\
\text { results; limitations; conclusions and implications of key findings; systematic review registration } \\
\text { number }\end{array}$ \\
\hline \multicolumn{3}{|l|}{ Introduction } \\
\hline Rationale & 3 & Describe the rationale for the review in the context of what is already known \\
\hline Objectives & 4 & $\begin{array}{l}\text { Provide an explicit statement of questions being addressed with reference to participants, interven- } \\
\text { tions, comparisons, outcomes, and study design (PICOS) }\end{array}$ \\
\hline \multicolumn{3}{|l|}{ Methods } \\
\hline Protocol and registration & 5 & $\begin{array}{l}\text { Indicate if a review protocol exists, if and where it can be accessed (e.g., Web address), and, if } \\
\text { available, provide registration information including registration number }\end{array}$ \\
\hline Eligibility criteria & 6 & $\begin{array}{l}\text { Specify study characteristics (e.g., PICOS, length of follow-up) and report characteristics (e.g., } \\
\text { years considered, language, publication status) used as criteria for eligibility, giving rationale }\end{array}$ \\
\hline Information sources & 7 & $\begin{array}{l}\text { Describe all information sources (e.g., databases with dates of coverage, contact with study } \\
\text { authors to identify additional studies) in the search and date last searched }\end{array}$ \\
\hline Search & 8 & $\begin{array}{l}\text { Present full electronic search strategy for at least one database, including any limits used, such } \\
\text { that it could be repeated }\end{array}$ \\
\hline Study selection & 9 & $\begin{array}{l}\text { State the process for selecting studies (i.e., screening, eligibility, included in systematic review, } \\
\text { and, if applicable, included in the meta-analysis) }\end{array}$ \\
\hline Data collection process & 10 & $\begin{array}{l}\text { Describe the method of data extraction from reports (e.g., piloted forms, independently, in dupli- } \\
\text { cate) and any processes for obtaining and confirming data from investigators }\end{array}$ \\
\hline Data items & 11 & $\begin{array}{l}\text { List and define all variables for which data were sought (e.g., PICOS, funding sources) and any } \\
\text { assumptions and simplifications made }\end{array}$ \\
\hline $\begin{array}{l}\text { Risk of bias in individual } \\
\text { studies }\end{array}$ & 12 & $\begin{array}{l}\text { Describe the methods used for assessing the risk of bias of individual studies (including specifica- } \\
\text { tion of whether this was done at the study or outcome level), and how this information is to be } \\
\text { used in any data synthesis }\end{array}$ \\
\hline Summary measures & 13 & State the principal summary measures (e.g., risk ratio, difference in means) \\
\hline Synthesis of results & 14 & $\begin{array}{l}\text { Describe the methods of handling data and combining results of studies, if done, including meas- } \\
\left.\text { ures of consistency (e.g., } \mathrm{I}^{2}\right) \text { for each meta-analysis }\end{array}$ \\
\hline Risk of bias across studies & 15 & $\begin{array}{l}\text { Specify any assessment of the risk of bias that may affect the cumulative evidence (e.g., publica- } \\
\text { tion bias, selective reporting within studies) }\end{array}$ \\
\hline Additional analyses & 16 & $\begin{array}{l}\text { Describe the methods of additional analyses (e.g., sensitivity or subgroup analyses, meta-regres- } \\
\text { sion), if done, indicating which were pre-specified }\end{array}$ \\
\hline \multicolumn{3}{|l|}{ Results } \\
\hline Study selection & 17 & $\begin{array}{l}\text { Give the numbers of studies screened, assessed for eligibility, and included in the review, with } \\
\text { reasons for exclusions at each stage, ideally with a flow diagram }\end{array}$ \\
\hline Study characteristics & 18 & $\begin{array}{l}\text { For each study, present characteristics for which data were extracted (e.g., study size, PICOS, } \\
\text { follow-up period) and provide the citations }\end{array}$ \\
\hline Risk of bias within studies & 19 & $\begin{array}{l}\text { Present data on the risk of bias of each study and, if available, any outcome level assessment (see } \\
\text { Item 12) }\end{array}$ \\
\hline Results of individual studies & 20 & $\begin{array}{l}\text { For all outcomes considered (benefits or harms), present, for each study: (a) simple summary data } \\
\text { for each intervention group, (b) effect estimates and confidence intervals, ideally with a forest } \\
\text { plot }\end{array}$ \\
\hline Synthesis of results & 21 & $\begin{array}{l}\text { Present the main results of the review. If meta-analyses are done, include for each, confidence } \\
\text { intervals and measures of consistency } \\
\text { Updated in accordance with http://prisma-statement.org/PRISMAStatement/Checklist }\end{array}$ \\
\hline Risk of bias across studies & 22 & Present results of any assessment of the risk of bias across studies (see Item 15) \\
\hline Additional analysis & 23 & $\begin{array}{l}\text { Give results of additional analyses, if done (e.g., sensitivity or subgroup analyses, meta-regression } \\
\text { [see Item 16]) }\end{array}$ \\
\hline
\end{tabular}


Table 1 (continued)

\begin{tabular}{lcc}
\hline Section/topic & $\#$ & Checklist item \\
\hline $\begin{array}{l}\text { Discussion } \\
\text { Summary of evidence }\end{array}$ & 24 & $\begin{array}{c}\text { Summarize the main findings including the strength of evidence for each main outcome; consider } \\
\text { their relevance to key groups (e.g., healthcare providers, users, and policymakers) } \\
\text { Discuss limitations at study and outcome level (e.g., risk of bias) and at review level (e.g., incom- } \\
\text { plete retrieval of identified research, reporting bias) }\end{array}$ \\
Limitations & 25 & $\begin{array}{c}\text { Provide a general interpretation of the results in the context of other evidence and implications for } \\
\text { future research }\end{array}$ \\
$\begin{array}{l}\text { Funding } \\
\text { Funding }\end{array}$ & 27 & $\begin{array}{c}\text { Describe sources of funding for the systematic review and other support (e.g., supply of data); role } \\
\text { of funders for the systematic review }\end{array}$ \\
\hline
\end{tabular}

effects). Unstated data were designated as non-available (N/A). The extracted data were compiled into evidence tables to facilitate descriptive analysis.

\section{Results}

The literature search identified 2172 potential symposium abstracts and 144 potential publications from PubMed. A total of 27 symposium abstracts and 22 publications were deemed appropriate for final inclusion based on the eligibility criteria outlined in Fig. 1. This included 5 reports from 3 randomized controlled trials ( 1 publication; 4 abstracts) and 44 reports from 40 observational trials and 1 case series
(21 publications; 23 abstracts), representing a total of 44 distinct studies.

\section{Evidence from Randomized Controlled Trials}

Data from a total of 3 distinct randomized controlled trials were reported in either published articles or abstract format and accounted for just 5 of the 49 publications included in this review. Of these 3 trials, data from the NOR-SWITCH trial were reported in 1 published article and 2 conference abstracts (Table 2). This randomized, double-blind, parallel group, non-inferiority trial evaluated the safety and efficacy of switching from infliximab to CT-P13 versus infliximab maintenance treatment across 6 inflammatory diseases [10].
Primary search$$
\text { ECCO (2013 - 2018) }
$$$$
\text { "infliximab AND biosimilar AND }
$$$$
\text { (inflammatory OR IBD)" }
$$$$
\begin{aligned}
& \text { DDW (2013 - 2017) } \\
& \text { "infliximab AND biosimilar" }
\end{aligned}
$$

Screening based on inclusion criteria
2172 results
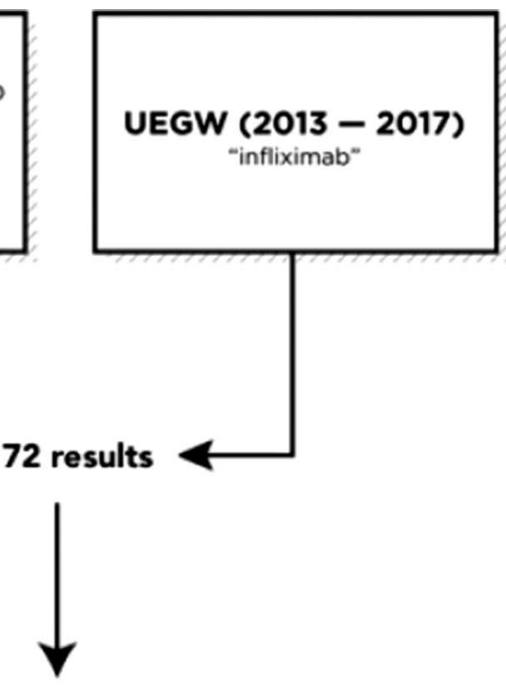

27 results

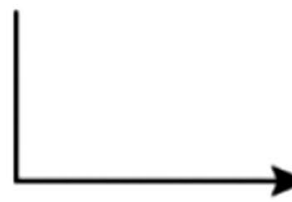

PubMed

"(switch OR switching OR interchange $O R$ interchanged) AND infliximab AND (ulcerative colitis OR inflammatory bowel disease OR Crohn)"
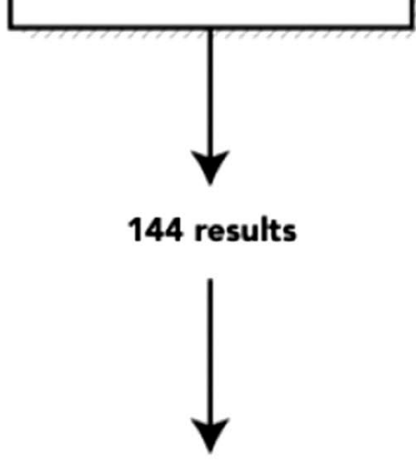

22 results

Fig. 1 Flowchart of literature search outcomes 


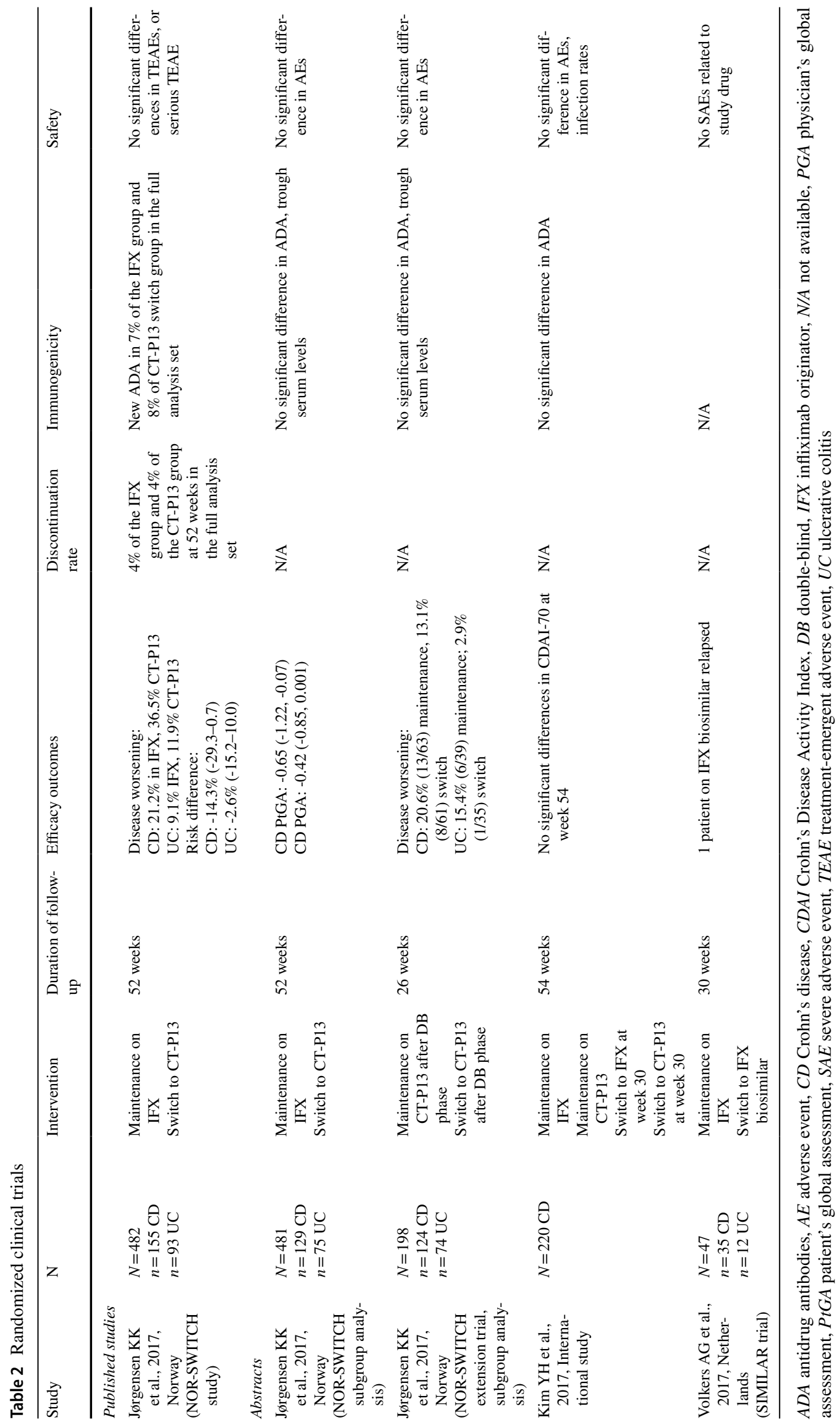


Patients enrolled in the 52-week NOR-SWITCH trial were $\geq 18$ years of age with RA, spondyloarthritis (SpA), PsA, UC, CD, or PsO, and clinically stable on infliximab for $\geq 6$ months. The primary endpoint was a composite endpoint of disease worsening, presumably designed to increase event rate and reflect the pragmatic nature of the trial (UC: increase in partial Mayo [p-Mayo] score of $\geq 3$ and a p-Mayo score of $\geq 5$; CD: increase in Harvey-Bradshaw Index [HBI] of $\geq 4$ and a HBI score of $\geq 7$; RA/PsA: increase in Disease Activity Score in 28 joints [DAS28] of $\geq 1.2$ from randomization and a DAS28 of $\geq 3.2$; AS/SpA: increase in Ankylosing Spondylitis Disease Activity Score [ASDAS] of $\geq 1.1$ and ASDAS of $\geq 2.1$; PsO: increase in Psoriasis Area and Severity Index [PASI] of $\geq 3$ from randomization and a minimum PASI of $\geq 5$ ). A $15 \%$ non-inferiority margin was used at $90 \%$ power [10].

The authors concluded that CT-P13 was non-inferior to infliximab based on the disease worsening composite endpoint ( $29.6 \%$ vs. $26.2 \%$, respectively), with a risk difference of $-4.4 \%$ (95\% confidence interval [CI]; - 12.7-3.9) adjusted for diagnosis and treatment duration of infliximab originator at baseline. Independently, results in 5 out of 6 disease categories failed to demonstrate non-inferiority. In $\mathrm{CD}$, the risk difference for switching was $-14.3 \%$ (95\% CI -29.3-0.7) [10, 11]. In UC, disease worsening was observed in $9.1 \%$ and $11.9 \%$ of switch and infliximab maintenance patients, respectively, with a risk difference of $-2.6 \%(95 \%$ CI - 15.2-10.0) [10]. However, these analyses should be considered exploratory, as the trial design was not powered to examine subgroups.

Recently, Jørgensen et al. presented an IBD subgroup analysis from the 26-week, NOR-SWITCH open-label extension trial [12]. Stable switch patients on CT-P13 were enrolled into the maintenance arm after the initial 52-week trial, while those on infliximab maintenance were switched to CT-P13. The primary endpoint was disease worsening according to HBI for CD and the p-Mayo score for UC. Disease worsening occurred in $20.6 \%$ versus $13.1 \%$ CD patients (risk difference $7.9 \%, 95 \% \mathrm{CI}-5.2-21$ ) and $15.4 \%$ versus $2.9 \%$ UC patients (risk difference $12.4 \%, 95 \% \mathrm{CI}-0.1-25$ ) on CT-P13 maintenance versus those switching from infliximab, respectively. Though low enrollment numbers precluded conclusive implications to be drawn, the authors stated that efficacy, safety, and immunogenicity were similar between treatment arms [12].

The second randomized controlled trial included was presented by Kim et al. at ECCO 2017 (NCT02096861) [13]. This 54-week, phase III randomized, double-blind, parallel group, non-inferiority trial examined the efficacy and overall safety of CT-P13 versus infliximab in 220 patients with active CD. Patients were randomized to CT-P13 or infliximab and followed for 30 weeks. At week 30, patients in each respective arm were re-randomized to either continue their current therapy or switch, resulting in a total of 4 treatment arms. The primary objective of the study was to compare the efficacy between CT-P13 and infliximab in terms of Crohn's Disease Activity Index-70 (CDAI-70) response rates, defined as a reduction in at least 70 points from baseline CDAI score at week 6 . There was no difference in the primary endpoint between arms (CT-P13, 71.4\%; infliximab, $75.2 \% ; p=0.5613$ ). The study also examined secondary outcomes associated with CDAI-100 response (reduction in at least 100 points in baseline CDAI score) and clinical remission rates (absolute CDAI score of less than 150 points). Similar trends to CDAI-70 were observed for the more stringent and traditional outcome of CDAI-100 (CT-P13, 61.9\%; infliximab, $64.4 \% ; p=0.7744)$ and clinical remission rates (CT-P13, 42.9\%; infliximab, 44.6\%; $p=0.8329$ ) at week 6 [13]. A similar proportion of patients between treatment arms were found to have at least one treatment-emergent serious adverse event (CT-P13, 1.8\% [2/111]; infliximab, $1.8 \%$ [2/109]) [13].

Preliminary results of the third and final included randomized controlled trial were presented by Volkers et al. at UEGW 2017 (NCT02452151) [14]. This randomized, controlled, double-blind, phase IV, non-inferiority trial examined CD and UC patients in clinical and biochemical remission while on infliximab therapy who were randomized to either CT-P13 or infliximab maintenance treatment. The primary endpoint was remission at week 30 . A total of 47 patients ( $35 \mathrm{CD}, 12 \mathrm{UC}$ ) had been recruited as of October 2017, of whom 21 completed the 30-week follow-up (15 received CT-P13 and 6 infliximab). One patient on CT-P13 experienced a loss of response, and no immunogenicity data were provided. Though preliminary, the authors concluded that switching from infliximab to the biosimilar is feasible and safe [14].

\section{Evidence from Published Observational Switch Studies}

Published observational studies accounted for 21 of the total 49 reports included in this review. Due to the significant inter-study heterogeneity of the patient populations, baseline characteristics, dosing schedules, and follow-up periods, a meaningful comparison between the published observational switch studies becomes difficult to conduct and interpret. For example, 6 out of 21 published observational studies (Table 3) reported a loss of effectiveness over the study period for both $\mathrm{CD}$ and UC patient populations, with values ranging from 6.3 to $30.2 \%$ and 0 to $22 \%$, respectively [15-20]. Five studies reported a loss of response for IBD switch groups as a whole, varying from 0 to $24.6 \%$ [21-25]. The observational study by Ratnakumaran et al. was the only one that utilized a control group on infliximab maintenance therapy and also reported on the secondary loss of response 


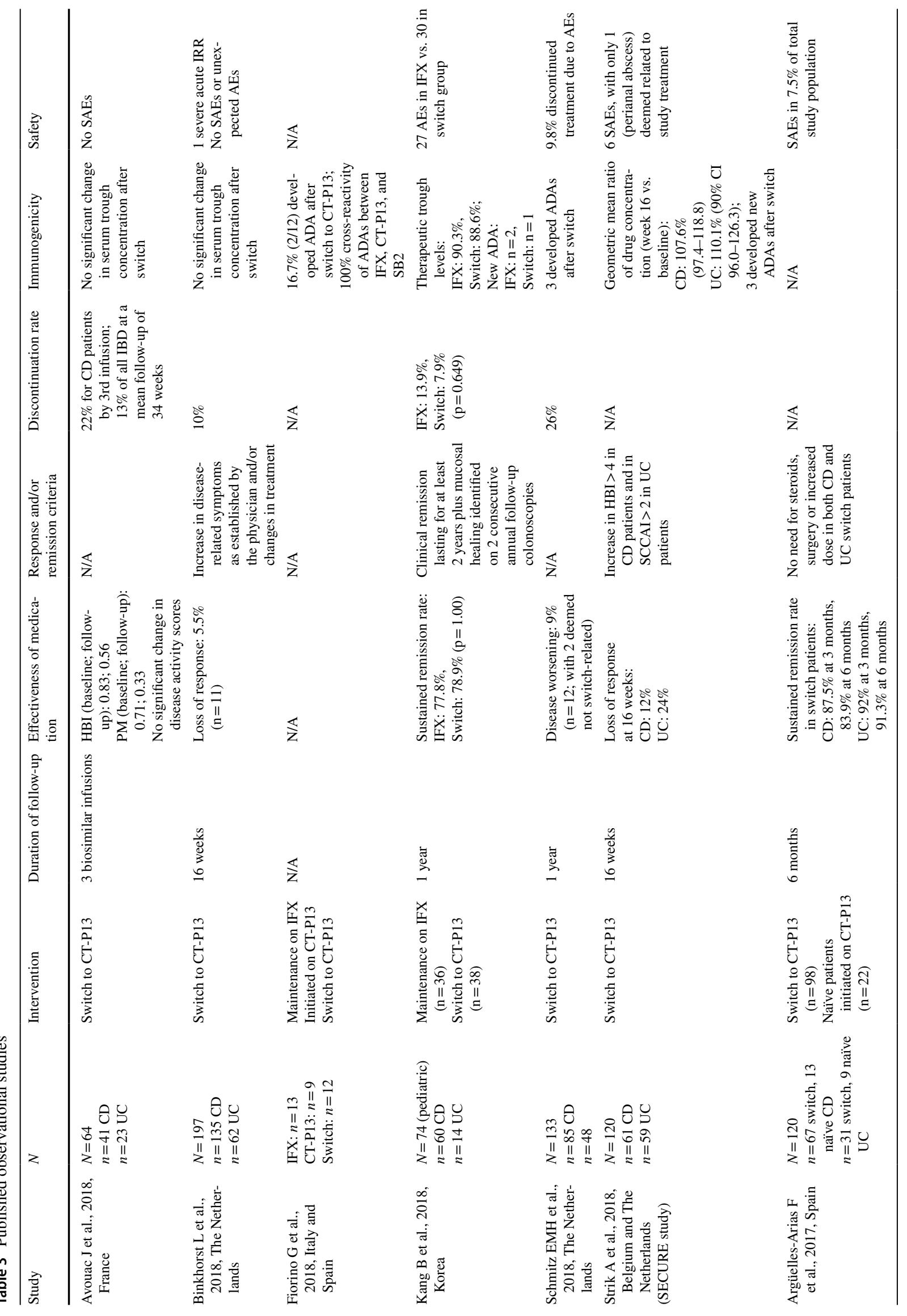




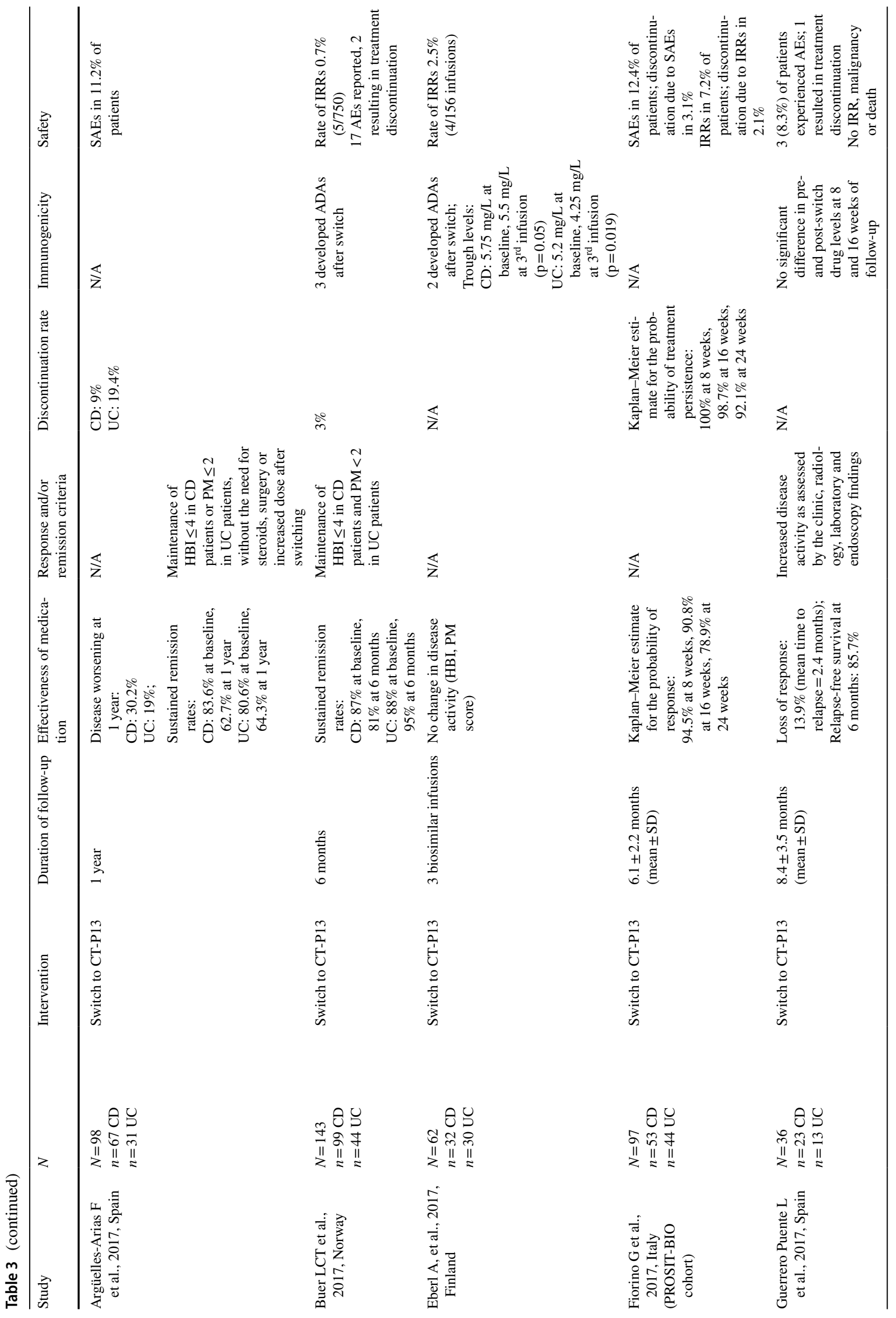




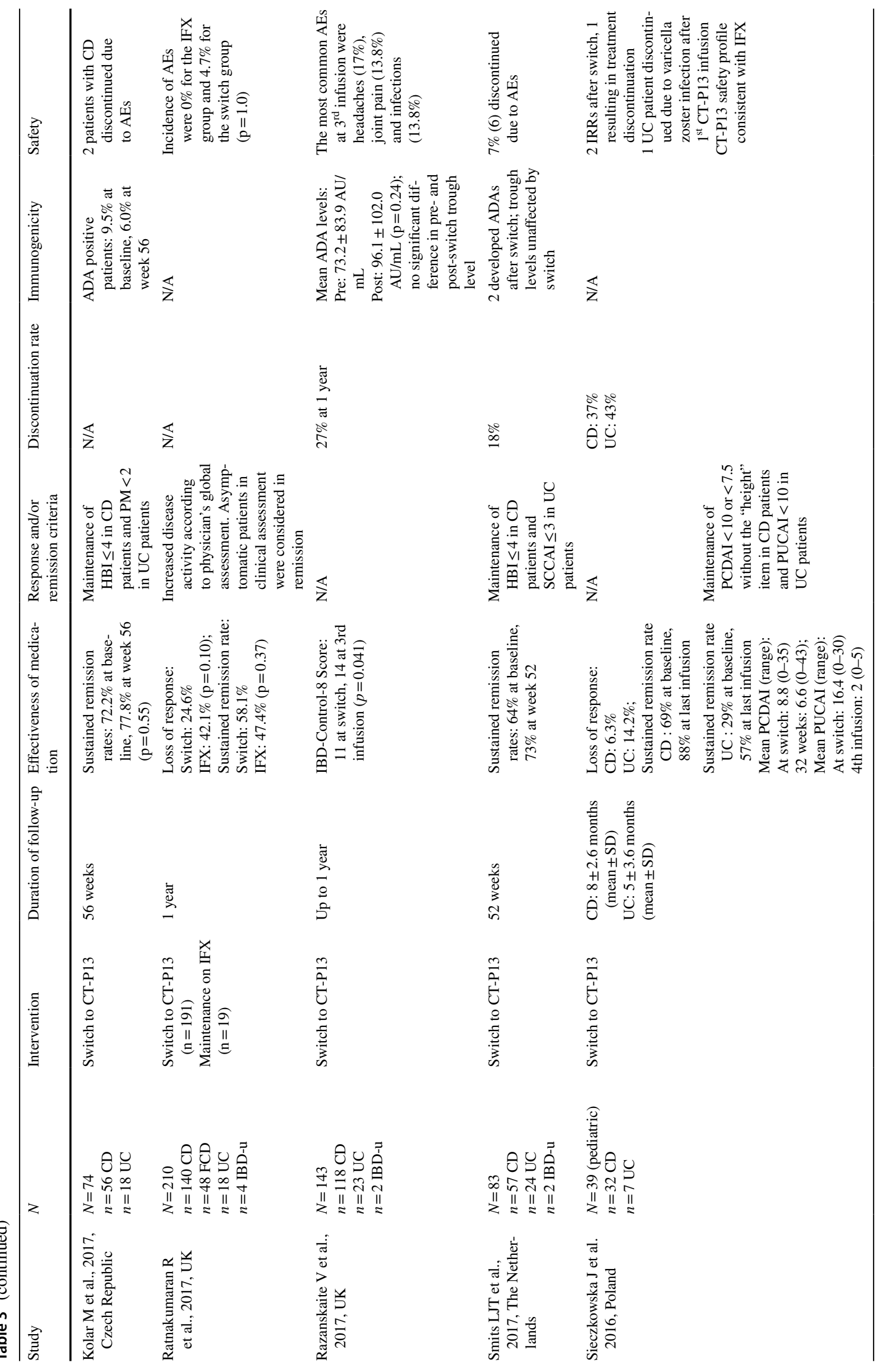




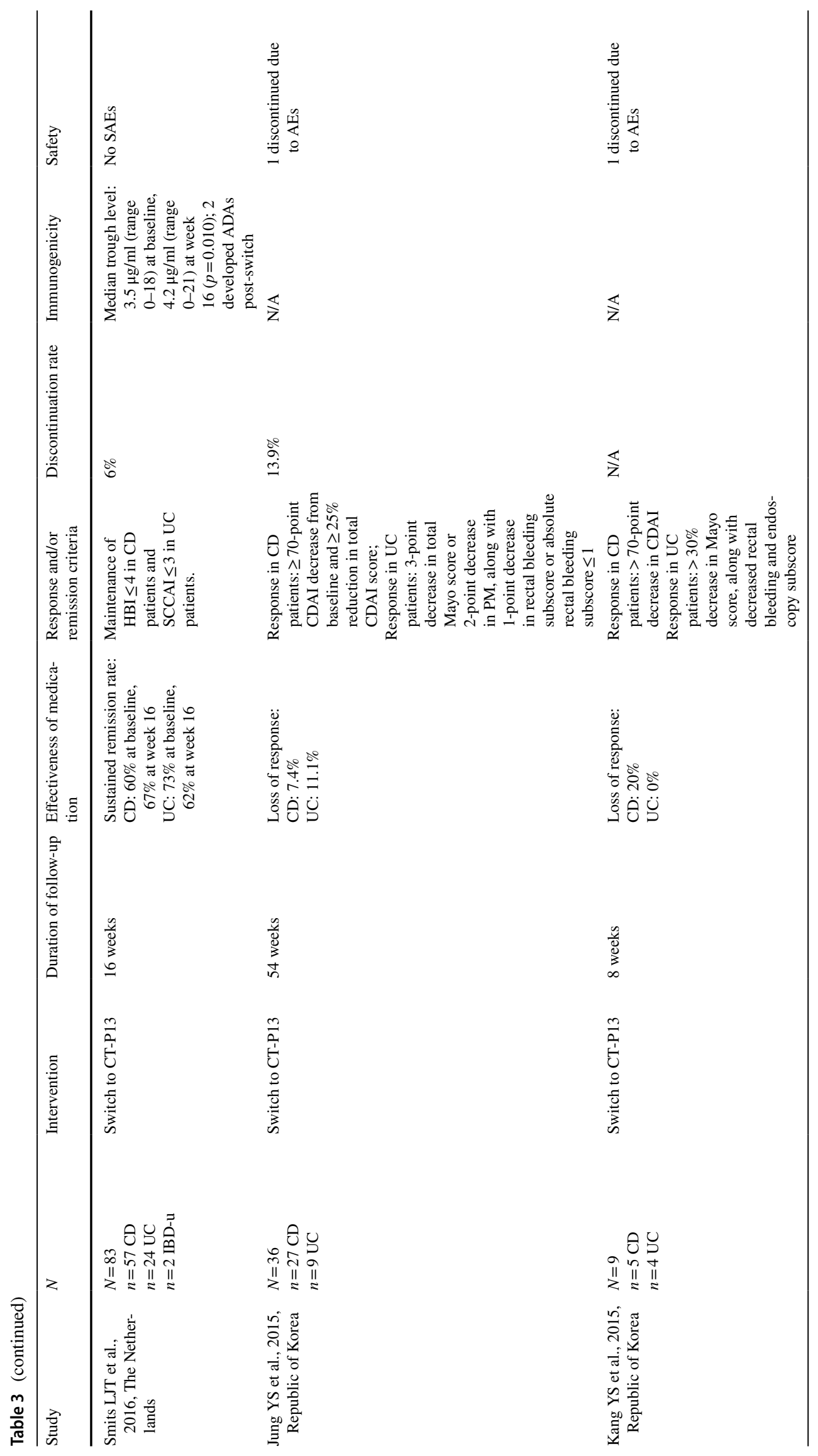




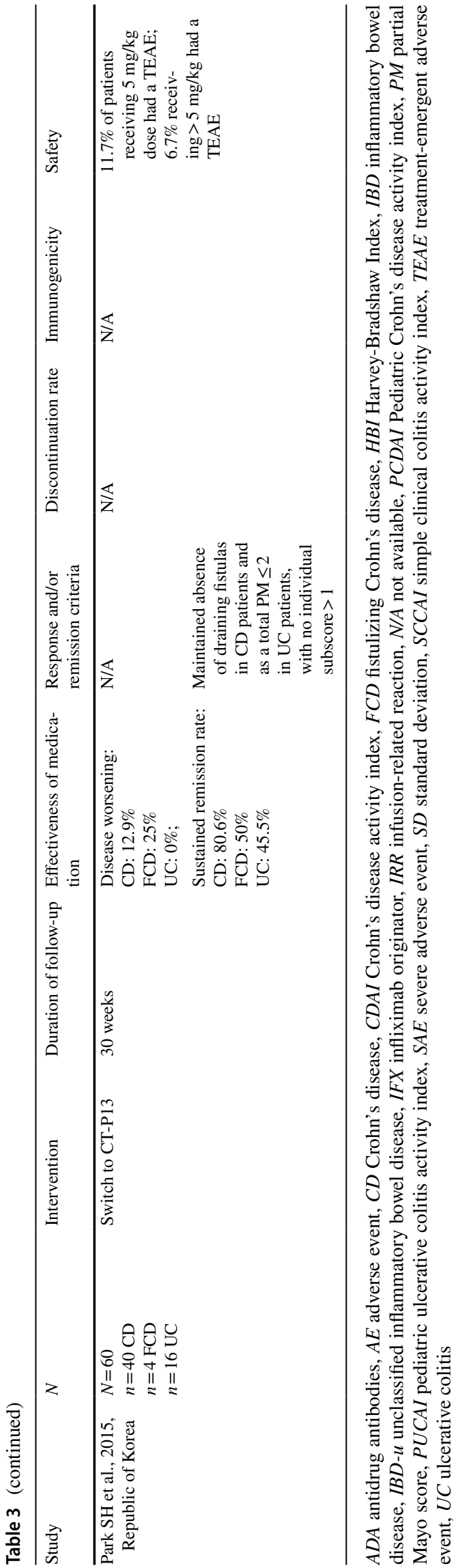

post-switch. The authors concluded that observed inter-arm differences were statistically insignificant [22]. Discontinuation rates were reported for 12 out of 21 studies and ranged from 3 to $27 \%$ for the IBD switch groups and 9 to $37 \%$ and 19.4 to $43 \%$ for CD and UC switch groups, respectively [16, 19-21, 24-31]. Immunogenicity and safety data across the studies were diverse, but often lacked a control arm for comparison [15-35]. This variability makes it difficult for broad generalizations regarding the safety and effectiveness of non-medical switch to be made.

\section{Evidence from Observational Studies in Conference Abstracts}

Data from observational studies presented as posters or abstracts at the selected international gastroenterology conferences accounted for 23 of the 49 total reports included in this review (Table 4) [36-58]. Similarly to the published empirical data, there was significant heterogeneity in patient populations, concomitant medications, and follow-up periods. Results demonstrated high variability in effectiveness, immunogenicity, and safety, with no studies utilizing an infliximab maintenance control arm. Loss of effectiveness for the combined IBD switch population was specifically highlighted in just 6 out of 23 studies, ranging from 4.2 to $25.0 \%$ [40, 43, 44, 46, 52, 54, 57]. Suk et al. was the only study to clearly specify loss of response in the CD and UC switch populations, at $14 \%$ and $33 \%$, respectively [58]. Variability in the reported discontinuation rates and immunogenicity outcomes was also observed (Table 4).

Ilias et al. recently presented an abstract addressing the paucity of evidence on reverse switch to infliximab (i.e., switching back to infliximab after initial switch to CT-P13) [49]. Since 2014, all infliximab-naïve patients, and those who had not been exposed for at least 12 months, were mandated to start CT-P13 in Hungary. In August 2017, policy changes resulted in a mandatory reverse switch for all patients on CT-P13, back to originator infliximab. Data were collected from 117 stable CD and UC patients on CT-P13 maintenance from four IBD centers at the time of the reverse switch and 24 weeks post-reverse switch. Concomitant immunomodulators and steroids were used in $53.8 / 45.8 \%$ and $7.5 / 37.5 \%$ of $\mathrm{CD} / \mathrm{UC}$ patients at the reverse switch, respectively. All but one patient, who experienced an infusion-related reaction, tolerated the first infusion after the reverse switch.

\section{Evidence from Published Observational Studies with Updated Data in Conference Abstracts}

Currently, the observational study with the most robust enrollment is for the PROSIT-BIO cohort, which used a 


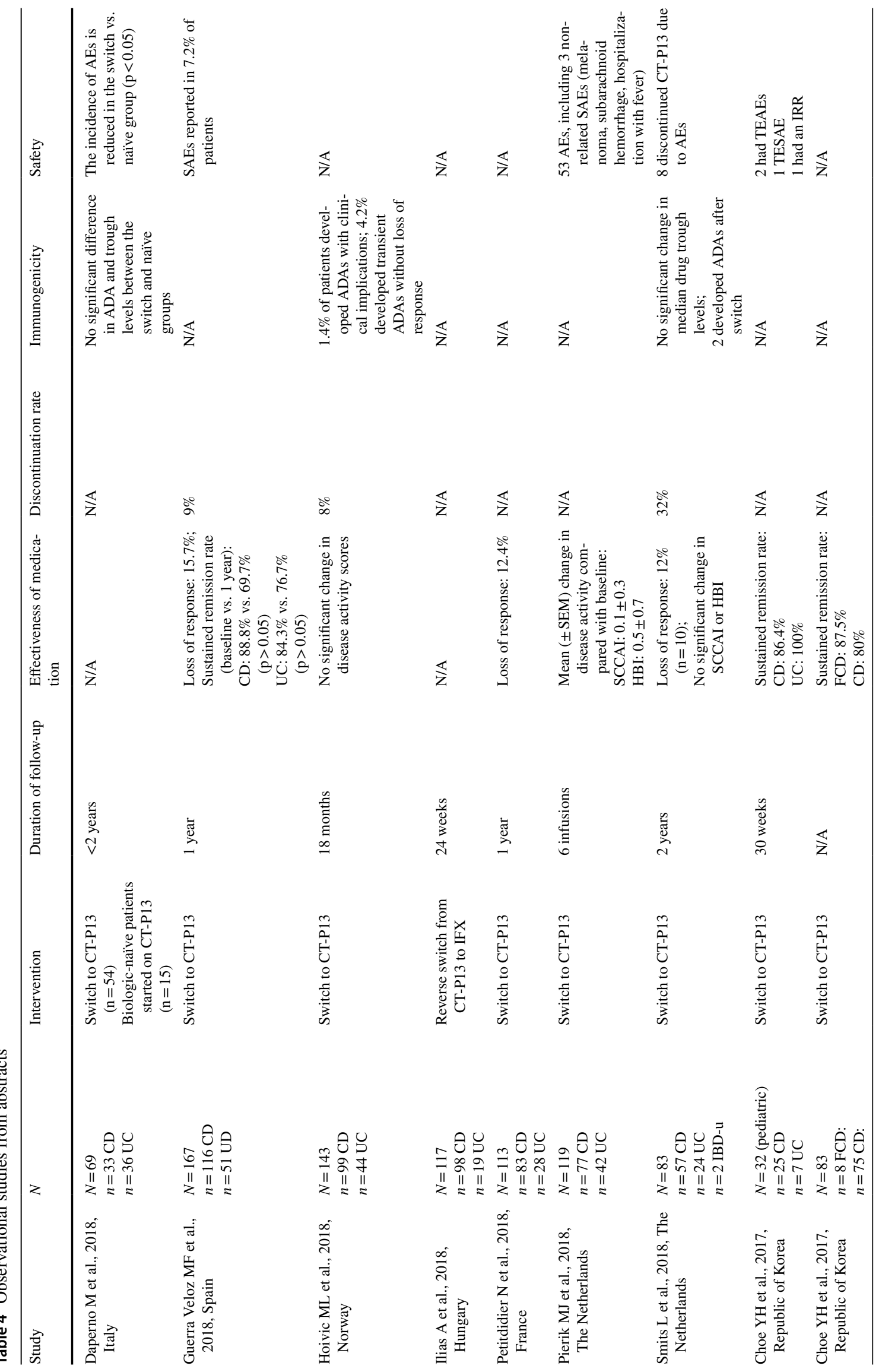




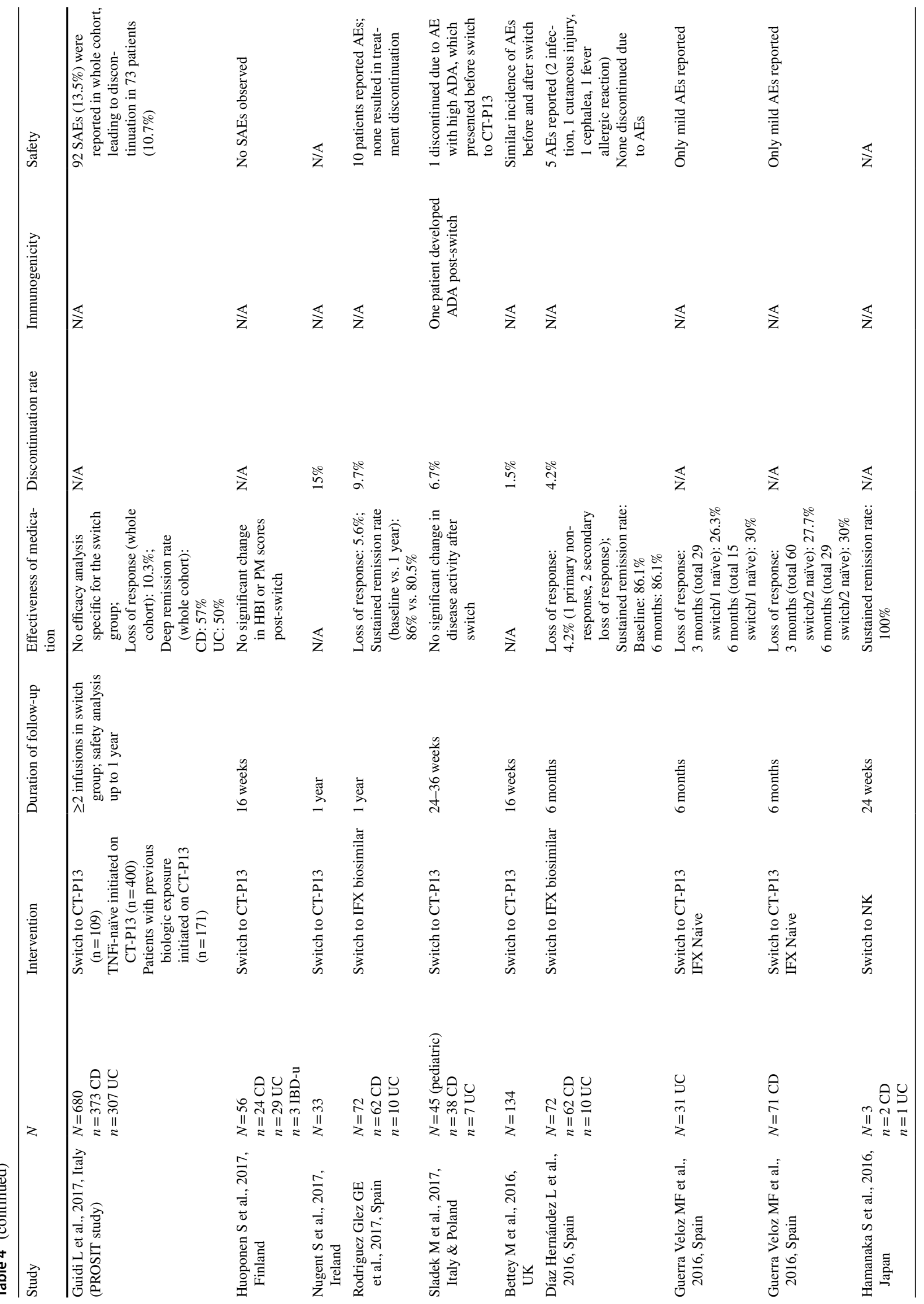




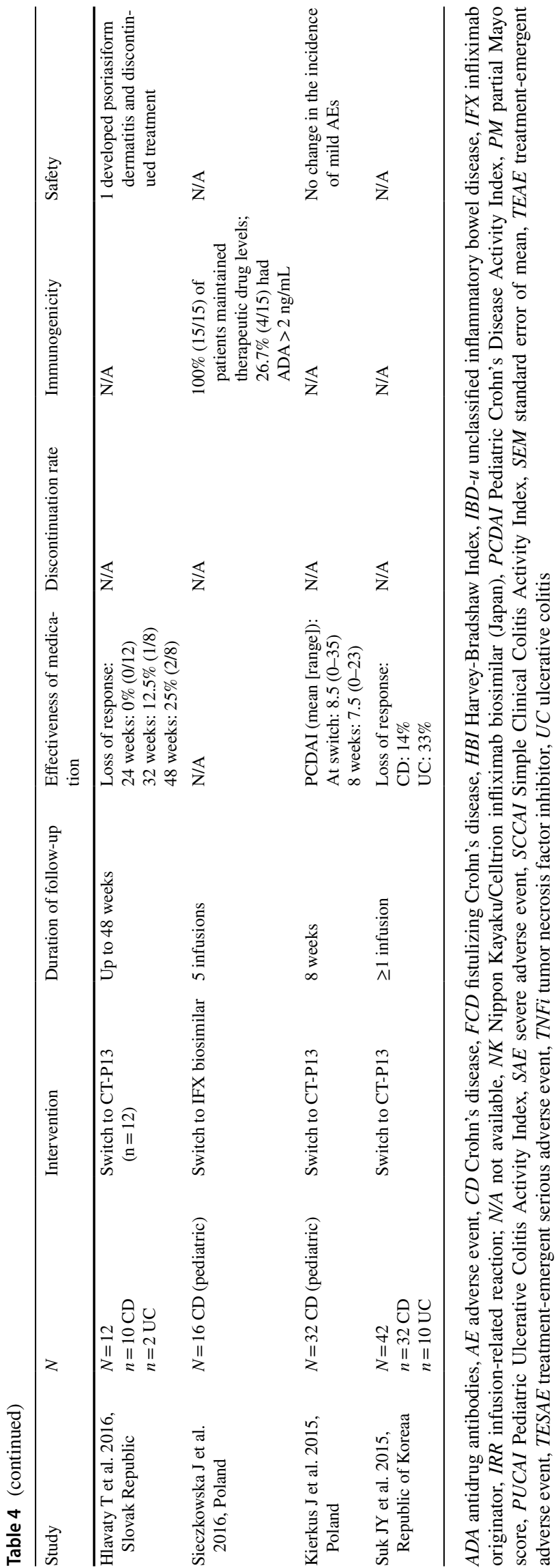

structured database that included 547 consecutive CD and UC patients from 31 referral centers treated with CT-P13 [24]. The majority of these patients were anti-TNFo naïve $(n=311), 139$ had previous exposure to one or more biologics (median duration of drug holiday was 9 months for infliximab and 10 months for other anti-TNFs), and the remaining 97 were switched from infliximab to CT-P13 therapy (hereafter referred to as switch patients). No control arm was utilized in the study. After a median of 6 months of follow-up, primary failure was observed in $8.1 \%$ (35/434) of evaluable patients. In the first 8 weeks, there was no primary failure observed in switch patients (95\% CI: $0-3.8 \% ; p=0.005$ ). At 16, 24, and 32 weeks, the effectiveness estimations were $94.5 \%, 90.8 \%$, and $78.9 \%$, respectively, for the switch patients (log-rank $p=0.64)$, with no commentary offered on the loss of response. The probability for treatment nonpersistence in switch patients was estimated to be $1.3 \%$ and $7.9 \%$ at weeks 16 and 24, respectively. Serious adverse events were reported in $12.4 \%$ of switch patients, leading to discontinuations in $2.1 \%$ (2/97) of patients. Infusion reactions occurred in $7.2 \%$ of patients, at a rate 3 times more frequent than naïve patients [24]. Guidi et al. presented updated data for PROSIT-BIO at the 2017 Congress of ECCO, in which 680 patients were enrolled. Primary failure was observed in $8.1 \%$ of patients $(55 / 680)$, while a loss of response occurred in $10.3 \%(62 / 680)$ of all patients. There was no infliximabspecific switch data provided, making it challenging to determine the potential impact of non-medical switch to the biosimilar [44].

Data on long-term outcomes are usually scarce and typically limited to one year following biosimilar switch. Smits et al. examined the long-term efficacy, safety, and immunogenicity profile of non-medical switch from infliximab to CT-P13 in patients with IBD [26]. Patients enrolled in this single-center, prospective, open-label study consisted of 57 CD, 24 UC, and 2 "IBD unclassified" patients, who were initially followed for 52 weeks post-switch. No control arm was used in this study. The primary endpoint was a change in disease activity scores at week 52 compared to baseline, as measured by HBI for CD or Simple Clinical Colitis Activity Index (SCCAI) for UC and unclassified IBD. Remission rates were reported to be $64 \%$ at baseline and $73 \%$ at week 52 , with no data provided on the loss of response [26]. More recently, Smits et al. presented data at the 2018 Congress of ECCO on the effectiveness and safety of switch from infliximab to CT-P13 over a 2-year follow-up period, which represents the longest follow-up of an observational switch cohort currently available in the literature [57]. At week 104, 53 of 78 (68\%) patients remained on CT-P13, while 5 were lost to follow-up. Reasons for discontinuation during years 1 and 2 were disease worsening ( $n=2$ and 5 , respectively; total $8 \%$ ), loss of response ( $n=5$ and 5, respectively; total $12 \%$ ), and adverse events ( $n=6$ and 2, respectively; total 10\%). 
Median trough levels at baseline and weeks 52 and 104 were $3.6 \mu \mathrm{g} / \mathrm{ml}$ (interquartile range [IQR] 1.7-5.5), $3.7 \mu \mathrm{g} /$ $\mathrm{ml}$ (IQR 2.1-5.8), and $3.9 \mu \mathrm{g} / \mathrm{ml}$, respectively (IQR 2.2-5.7; $p=0.664$ ). Antidrug antibodies (ADAs) were present in 5 of $83(6 \%)$ patients at baseline (prior to switching) and in $2(2 \%)$ patients before week 52 . No subsequent ADAs were detected up to week 104. The majority of IBD patients (68\%) continued CT-P13 beyond 2 years after switching from innovator infliximab [57].

\section{Discussion}

We conducted a systematic review of randomized controlled trials, observational studies, and case series, in which stable patients with $\mathrm{UC}$ or $\mathrm{CD}$ were switched from originator infliximab to the CT-P13 biosimilar. In total, 49 reports from 44 distinct studies available up to April 2018 were included, expanding the literature examined on infliximab biosimilar switch presented over the last few years [59-63]. Given the paucity of published data from randomized controlled trials, most systematic reviews on infliximab biosimilar switch have referenced a limited number of observational studies $[62,63]$. Some publications have suggested that the current data support the safety of switching from originator infliximab to biosimilar in IBD patients [59, 60], whereas others have emphasized the need for studies on bidirectional biosimilar switch, as well as those that use appropriate control arms [61]. We present a comprehensive review evaluating the impact of switching to CT-P13 on efficacy/effectiveness and safety in CD and UC patients. In addition, this systematic review critically appraises methodologies of the studies generating the data that may influence the decision of switching stable patients from infliximab to CT-P13, and highlights their limitations.

Only 3 of the studies included in this systematic review were found to be randomized controlled trials, with NORSWITCH being the only trial fully published to date. Designed as a pragmatic real-life study, NOR-SWITCH examined treatment switch across 6 indications in approximately 500 patients (CD, $n=155$; UC, $n=93$; SpA, $n=91$; RA, $n=78$; PsO, $n=35$; and PsA, $n=30$ ). Limitations of the study design have been previously discussed [64]. For example, a composite measure of disease worsening was used, which included 6 highly heterogeneous inflammatory disease states each employing different disease activity measures, varying infliximab dosing regimens, and concomitant therapies. This, in addition to patient inclusion being largely based on a "clinical diagnosis" of stable disease with ill-defined disease-specific criteria, introduces the potential for bias and limits the inferences that can be extrapolated to IBD. The primary endpoint of disease worsening was also estimated to occur in $29.6 \%$ of patients treated with CT-P13 versus $26.2 \%$ on infliximab therapy. As the total enrollment number allowed for a $15 \%$ non-inferiority margin at $90 \%$ power, theoretically, $50 \%$ of CT-P13-treated patients could experience disease worsening without the primary endpoint being deemed inferior. Finally, while subgroup efficacy analyses were underpowered to detect differences, the trend toward increased disease worsening in $\mathrm{CD}$ patients has caused some concern in the gastrointestinal community and a desire for more robust data in IBD patients.

In order to address the potential concerns and limitations of NOR-SWITCH, Kim et al. conducted a double-blind study that enrolled a homogenous patient population with active $\mathrm{CD}$, utilized appropriate control arms, and allowed for dose escalation [13]. It was the first randomized controlled trial that examined the efficacy and safety of a one-way switch from CT-P13 to infliximab in this patient population and investigated a number of secondary endpoints (e.g., pharmacokinetics, safety, ADA development, and quality of life). Randomization of 220 patients across 4 switch arms results in approximately 55 patients per arm (not accounting for attrition). Assuming a power level of $80 \%$ and $p<0.05$ for statistical significance, the margin of difference would be approximately $20 \%$ at 6 weeks. A more stringent noninferiority margin of $5-10 \%$ would require a larger sample size than the 220 patients included in this trial. This study also utilized CDAI-70 response at week 6 as the primary endpoint [13]. Standard CDAI assesses remission, not response, typically being measured at weeks 8 or 12 , and typically a more stringent definition of CDAI-100 is used for response. It is unclear whether 6 weeks is a sufficient duration for a response signal to manifest and if the shorter duration to primary endpoint creates a bias toward demonstrating non-inferiority.

Volkers et al. are currently conducting the first phase IV, double-blind, randomized, non-inferiority clinical trial comparing IBD patients who were switched from infliximab to CT-P13 [14]. Inclusion criteria required patients to be in clinical remission $(\mathrm{HBI}<5$ and Mayo $<2)$ and have a fecal calprotectin $<250 \mathrm{mg} / \mathrm{g}$. The primary endpoint is the number of patients in remission at week 30 . Though utilization of the HBI and Mayo questionnaires to determine remission may facilitate the feasibility of a phase IV trial, it does not allow for endoscopic verification of remission, particularly when switching stable patients.

Real-world data can offer valuable insight into the clinical effectiveness and safety of a therapy, prescribing patterns, and quality of life outcomes. The major disadvantage of these studies is the lack of randomization or appropriate control arms. Efficacy and safety assessments are also unlikely to be as robust as those in randomized controlled trials. Though many patients in published observational switch studies appeared to experience disease control, uncontrolled variables may influence perceived 
drug-outcome correlations, and models may not entirely account for confounding factors, rendering therapies to be seemingly equivalent. This underscores the caution that must be taken when switching stable IBD patients.

A recent meta-analysis attempted to address these concerns by examining published observational switch studies and analyzing data by disease type and duration of followup. Due to the heterogeneity of the patient populations, each analyzed group was comprised of only 1-2 studies, making inferences of the analysis difficult to assess [62]. The lack of published data has also been a limiting factor for meta-analyses. For instance, among the observational studies included in this systematic review, only half had been published by the time of submission. Unfortunately, this leads to a narrow understanding of important study details, the knowledge of which could affect readers' perception of study results.

The present systematic review has several limitations, including the small number of randomized controlled trials; predominance of observational studies with varying outcome assessments, lack of appropriate controls, and absence of data on loss of response and treatment discontinuation; and scarcity of research on long-term effects of biosimilar switch in CD and UC patients. The inclusion of conference abstracts can also be considered a limitation. While their inclusion may help to minimize publication bias, conference abstracts do not provide a complete description of methods and results to allow an evaluation of the rigor in which the research was conducted. In addition, the risk of bias for individual studies used in this review could not be assessed, as this would be subjective due to the biased nature of observational studies, which make up the majority of the studies included. Since this review mainly provides a critique of the methodologies used to generate the majority of data on biosimilar switch from infliximab to CT-P13, the lack of risk assessment does not affect its conclusions.

To date, the totality of evidence would suggest that switching infliximab patients to CT-P13 is generally safe and effective for most individuals. It remains unclear what the long-term impact is on those who are negatively affected by non-medical switching, the role that immunogenicity may play, and what physicians are willing to consider an acceptable risk.

\section{Impact of Non-medical Switch on Immunogenicity}

ADAs are a common occurrence with anti-TNF $\alpha$ therapies [65]. Indeed, the pivotal trials from a number of anti-TNF $\alpha$ products have demonstrated that the rate of ADAs ranges from approximately 1 to 30\% [2, 66-69]. Despite the propensity of ADA development, there are a number of challenges in terms of their quantification and impact assessment.
A recent European Medicines Agency guideline stated that ADA assays may often bind to the therapeutic product itself and thus require significant modifications to accommodate for inaccurate signals. However, such modifications can decrease the sensitivity and accuracy of the assay [70]. It has also been suggested that comparative assessment of immunogenicity be comprised of more than incidence rates between originator and biosimilar and include titers and titer distribution [71]. These factors, combined with the inherent differences within patient populations, hamper the comparability of ADAs across clinical trials.

Above all, the precise factors that cause an immunogenic response in patients are likely due to various treatment-, product-, and patient-related considerations [72, 73]. Gonczi et al. demonstrated the potential impact of drug holidays on those using infliximab. CD patients exposed to infliximab over 12 months prior to initiating CT-P13 therapy demonstrated significantly reduced clinical response and remission up to week $54(p<0.005)$ and higher ADA levels in early treatment (week $2, p<0.001$ ). Previously treated UC patients demonstrated significantly reduced clinical remission $(p \leq 0.03)$ and ADA development up to week 6 $(p<0.02)$ versus infliximab-naïve UC patients [74]. No differences were observed at weeks 14 or 30 . Final one-year results of this study confirmed the clinical impact of previous infliximab exposure and highlighted the increased likelihood to develop infusion reactions $[75,76]$.

To date, real-world infliximab switch studies in IBD do not have robust or long-term ADA assessments and are not powered to detect significant differences in immunogenicity. The lack of clarity regarding immunogenicity, combined with the inherent variability in ADA assays and loss of response rates observed thus far, reinforces a need for high-quality studies.

\section{Potential Multiple Switch Scenarios}

A number of infliximab biosimilars are likely to gain market authorization over the next few years. Several regulatory agencies have started to establish more stringent guidelines for demonstrating interchangeability between a reference drug and its biosimilar [77]. However, with very limited data on single reverse switches, and no trials examining multiple switches with infliximab, healthcare practitioners are currently ill-informed of the ADA risks and complications that may arise from frequent non-medical switch due to preferential listing or product tendering.

It is prudent that regulatory bodies take appropriate steps to ensure patient safety in this changing environment, as the existence of multiple infliximab biosimilars would make clinical trials extremely complex, and examination of all product-switch permutations unfeasible. Moreover, the increase in untested exposure to potentially different 
epitopes of infliximab and its biosimilars (particularly if the structures diverge over time), combined with the variability in patient-related factors, is likely to increase the unpredictability of immune responses [64].

\section{Conclusion}

Despite the potential limitations of the NOR-SWITCH trial, it is currently the only published randomized controlled trial available to glean insights regarding the non-medical switch. Considering this paucity of well-controlled data, the gastroenterology community has largely based clinical decisions on evidence from heterogeneous patient populations in observational trials, which lack controls. Though the majority of these studies suggest that a non-medical switch is safe and effective for most individuals, healthcare professionals and regulatory bodies should be aware of the limitations of study designs when making inferences about the risks and benefits of switching stable IBD patients. Full publication of additional randomized controlled trials in IBD populations will be critical to further our understanding of the impact that such clinical or economic decisions will have on patients.

Acknowledgments Unfortunately, Richard N Fedorak died on November 8,2018 , and was thus unable to provide final approval prior to manuscript submission. Dr. Fedorak fulfilled all other authorship requirements. Medical writing assistance was provided by Synapse Medical Communications, Oakville, Ontario, Canada.

Funding Janssen Inc. funded the medical writing services and had no influence on the content or development of the paper. All authors' contributions followed ICMJE guidelines, and all authors approved the final version of the manuscript (with the exception, unfortunately, of RNF who died prior to submission and therefore did not provide final approval).

\section{Compliance with Ethical Standards}

Conflict of interest Edmond-Jean Bernard has served as a speaker and consultant for Janssen, Abbvie, Takeda, Shire, Ferring, Allergan, Pfizer, and Merck. Richard N. Fedorak has served as a speaker and consultant for AbbVie Canada, Inc. and Janssen Canada, Inc. Vipul Jairath has received consulting fees from AbbVie, Eli Lilly, GlaxoSmithKline, Arena pharmaceuticals, Genetech, Pendopharm, Sandoz, Merck, Takeda, Janssen, Robarts Clinical Trials, Topivert, and Celltrion, and speaker's fees from Takeda, Janssen, Shire, Ferring, Abbvie, and Pfizer.

Open Access This article is licensed under a Creative Commons Attribution-NonCommercial 4.0 International License, which permits any non-commercial use, sharing, adaptation, distribution and reproduction in any medium or format, as long as you give appropriate credit to the original author(s) and the source, provide a link to the Creative Commons licence, and indicate if changes were made. The images or other third party material in this article are included in the article's Creative Commons licence, unless indicated otherwise in a credit line to the material. If material is not included in the article's Creative Commons licence and your intended use is not permitted by statutory regulation or exceeds the permitted use, you will need to obtain permission directly from the copyright holder.To view a copy of this licence, visit http://creativecommons.org/licenses/by-nc/4.0/.

\section{References}

1. Lybecker K. The Biologics Revolution in the Production of Drugs. Fraser Institute; 2016.

2. Remicade Product Monograph. Beerse: Janssen Inc.; 2018.

3. Lindsley CW. New 2016 Data and Statistics for global pharmaceutical products and projections through 2017. ACS Chem Neurosci. 2017;8:1635-1636.

4. Larsen L, Drewes AM, Broberg MCH, et al. Changing infliximab prescription patterns in inflammatory bowel disease: a population-based cohort study, 1999-2014. Inflamm Bowel Dis. 2018;24:433-439.

5. Yu H, MacIsaac D, Wong JJ, et al. Market share and costs of biologic therapies for inflammatory bowel disease in the USA. Aliment Pharmacol Ther. 2018;47:364-370.

6. Rubin DT, Mody R, Davis KL, Wang CC. Real-world assessment of therapy changes, suboptimal treatment and associated costs in patients with ulcerative colitis or Crohn's disease. Aliment Pharmacol Ther. 2014;39:1143-1155.

7. Rocchi A, Benchimol EI, Bernstein CN, et al. Inflammatory bowel disease: a Canadian burden of illness review. Can J Gastroenterol. 2012;26:811-817.

8. Health Canada. Fact Sheet: Biosimilars. www.canada.ca/en/healt h-canada/services/drugs-health-products/biologics-radiopharm aceuticals-genetic-therapies/applications-submissions/guidancedocuments/fact-sheet-biosimilars.html; 2017.

9. Malik AN, Cox J, Keeping K. Will U.S. payers champion biosimilars? Value Health. 2015;18:A265.

10. Jørgensen KK, Olsen IC, Goll GL, et al. Switching from originator infliximab to biosimilar CT-P13 compared with maintained treatment with originator infliximab (NOR-SWITCH): a 52-week, randomised, double-blind, non-inferiority trial. Lancet. 2017;389:2304-2316.

11. Jørgensen KK, et al. Biosimilar infliximab (CT-P13) is not inferior to originator infliximab: explorative IBD subgroup analysis in Crohn's disease and ulcerative colitis from the NOR-SWITCH trial [DDW Abstract 249]. Presented at: Digestive Disease Week Annual Meeting, May 6-9, 2017, Chicago, Illinois.

12. Jørgensen KK, Goll GL, Sexton J, et al. Long-term efficacy and safety of biosimilar infliximab (CT-P13) after switching from originator infliximab: explorative subgroup analyses in IBD from the NOR-SWITCH EXTENSION trial [ECCO Abstract P483]. Presented at: 13th Congress of ECCO, February 14-17, 2018, Vienna, Austria.

13. Kim YH, Ye BD, Pesegova M, et al. Phase III randomized, double blind, controlled trial to compare biosimilar infliximab (CT-P13) with innovator infliximab in patients with active Crohn's disease: early efficacy and safety results [DDW Abstract 248]. Presented at: Digestive Disease Week Annual Meeting, May 6-9, 2017, Chicago, Illinois.

14. Volkers AG, Jansen JM. SIMILAR trial-Efficacy of infliximabbiological in patients with inflammatory bowel disease in remission - a randomized controlled, double blind, phase 4 non-inferiority trial [UEGW Abstract P0409]. United Eur Gastroenterol J. 2017;5:A307. 
15. Strik AS, van de Vrie W, Bloemsaat-Minekus JPJ, et al. Serum concentrations after switching from originator infliximab to the biosimilar CT-P13 in patients with quiescent inflammatory bowel disease (SECURE): an open-label, multicentre, phase 4 non-inferiority trial. Lancet Gastroenterol Hepatol. 2018;3:404-412.

16. Sieczkowska J, Jarzebicka D, Banaszkiewicz A, et al. Switching between infliximab originator and biosimilar in paediatric patients with inflammatory bowel disease. preliminary observations. $J$ Crohns Colitis. 2016;10:127-132.

17. Park SH, Kim YH, Lee JH, et al. Post-marketing study of biosimilar infliximab (CT-P13) to evaluate its safety and efficacy in Korea. Expert Rev Gastroenterol Hepatol. 2015;9:35-44.

18. Kang YS, Moon HH, Lee SE, Lim YJ, Kang HW. Clinical Experience of the Use of CT-P13, a Biosimilar to infliximab in patients with inflammatory bowel disease: a case series. Dig Dis Sci. 2015;60:951-956. https://doi.org/10.1007/s10620-014-3392-z

19. Jung YS, Park DI, Kim YH, et al. Efficacy and safety of CT-P13, a biosimilar of infliximab, in patients with inflammatory bowel disease: a retrospective multicenter study. J Gastroenterol Hepatol. 2015;30:1705-1712.

20. Arguelles-Arias F, Guerra Veloz MF, Perea Amarillo R, et al. Switching from reference infliximab to CT-P13 in patients with inflammatory bowel disease: 12 months results. Eur J Gastroenterol Hepatol. 2017;29:1290-1295.

21. Schmitz EMH, Boekema PJ, Straathof JWA, et al. Switching from infliximab innovator to biosimilar in patients with inflammatory bowel disease: a 12-month multicentre observational prospective cohort study. Aliment Pharmacol Ther. 2018;47:356-363.

22. Ratnakumaran R, To N, Gracie DJ, et al. Efficacy and tolerability of initiating, or switching to, infliximab biosimilar CT-P13 in inflammatory bowel disease (IBD): a large single-centre experience. Scand J Gastroenterol. 2018;53:700-707.

23. Guerrero Puente L, Iglesias Flores E, Benitez JM, et al. Evolution after switching to biosimilar infliximab in inflammatory bowel disease patients in clinical remission. Gastroenterol Hepatol. 2017;40:595-604.

24. Fiorino G, Manetti N, Armuzzi A, et al. The PROSIT-BIO cohort: a prospective observational study of patients with inflammatory bowel disease treated with infliximab biosimilar. Inflamm Bowel Dis. 2017;23:233-243.

25. Binkhorst L, Sobels A, Stuyt R, Westerman EM, West RL. Switching to a infliximab biosimilar: short-term results of clinical monitoring in patients with inflammatory bowel disease. Eur J Gastroenterol Hepatol. 2018;30:699-703.

26. Smits LJT, Grelack A, Derikx L, et al. Long-term clinical outcomes after switching from Remicade((R)) to biosimilar CT-P13 in inflammatory bowel disease. Dig Dis Sci. 2017;62:3117-3122.

27. Smits LJ, Derikx LA, de Jong DJ, et al. Clinical outcomes following a switch from Remicade(R) to the biosimilar CT-P13 in inflammatory bowel disease patients: a prospective observational cohort study. J Crohns Colitis. 2016;10:1287-1293.

28. Razanskaite V, Bettey M, Downey L, et al. Biosimilar infliximab in inflammatory bowel disease: outcomes of a managed switching programme. J Crohns Colitis. 2017;11:690-696.

29. Kang B, Lee Y, Lee K, Choi YO, Choe YH. Long-term outcomes after switching to CT-P13 in pediatric-onset inflammatory bowel disease: a single-center prospective observational study. Inflamm Bowel Dis. 2018;24:607-616.

30. Buer LC, Moum BA, Cvancarova M, Warren DJ, Medhus AW, Hoivik ML. Switching from $\operatorname{Remicade}(\mathrm{R})$ to $\operatorname{Remsima}(\mathrm{R})$ is well tolerated and feasible: a prospective, open-label study. J Crohns Colitis. 2017;11:297-304.

31. Avouac J, Molto A, Abitbol V, et al. Systematic switch from innovator infliximab to biosimilar infliximab in inflammatory chronic diseases in daily clinical practice: the experience of
Cochin University Hospital, Paris, France. Semin Arthritis Rheum. 2018;47:741-748.

32. Kolar M, Duricova D, Bortlik M, et al. Infliximab biosimilar (Remsima) in therapy of inflammatory bowel diseases patients: experience from one tertiary inflammatory bowel diseases centre. Dig Dis. 2017;35:91-100.

33. Fiorino G, Ruiz-Arguello MB, Maguregui A, et al. Full Interchangeability in regard to immunogenicity between the infliximab reference biologic and biosimilars CT-P13 and SB2 in inflammatory bowel disease. Inflamm Bowel Dis. 2018;24:601-606.

34. Eberl A, Huoponen S, Pahikkala T, Blom M, Arkkila P, Sipponen $\mathrm{T}$. Switching maintenance infliximab therapy to biosimilar infliximab in inflammatory bowel disease patients. Scand J Gastroenterol. 2017;52:1348-1353.

35. Arguelles-Arias F, Guerra Veloz MF, Perea Amarillo R, et al. Effectiveness and safety of CT-P13 (biosimilar infliximab) in patients with inflammatory bowel disease in real life at 6 months. Dig Dis Sci. 2017;62:1305-1312. https://doi.org/10.1007/s1062 0-017-4511-4

36. Bettey M, Downey L, Underhill C, et al. Outcomes of a managed switching programme changing IBD patients on established originator infliximab to biosimilar infliximab. [ECCO Abstract DOP029]. Presented at: 11th Congress of ECCO, March 19-19, 2016, Amsterdam, Netherlands.

37. Choe $\mathrm{YH}$, Lee SH, Park DI, et al. Effectiveness and safety in Crohn's disease patients who were treated with CT-P13 [ECCO Abstract P500]. Presented at: 12th Congress of ECCO, February 15-18, 2017, Barcelona, Spain.

38. Choe YH, Yang HR, Moon JS, et al. Effectiveness and safety of CT-P13 under routine care in paediatric patients with inflammatory bowel disease. [ECCO Abstract P487]. Presented at: 12th Congress of ECCO, February 15-18, 2017, Barcelona, Spain.

39. Daperno M, Guiotto C, Italia A, et al. Switching from infliximab originator to a first biosimilar is safe and effective: a single-centre series with through levels and anti-drug antibodies determination [ECCO Abstract P588]. Presented at: 13th Congress of ECCO, February 14-17, 2018, Vienna, Austria.

40. Díaz Hernández L, Rodriguez González GE, Vela González M, et al. Efficacy and safety of switching between originator and biosimilar infliximab in patients with inflammatory bowel disease in practical clinic: results to 6 months [ECCO Abstract P449]. Presented at: 11th Congress of ECCO, March 19-19, 2016, Amsterdam, Netherlands.

41. Guerra Veloz MF, Arguelles-Arias F, Perea Amarillo R, et al. Safety and efficacy of infliximab biosimilar (Remsima) in ulcerative colitis disease patients in clinical practice: results after 6-months treatment [ECCO Abstract P600]. Presented at: 11th Congress of ECCO, March 19-19, 2016, Amsterdam, Netherlands.

42. Guerra Veloz MF, Arguelles-Arias F, Perea Amarillo R, et al. Safety and efficacy of infliximab biosimilar (Remsima) in Crohn's disease patients in clinical practice: results after 6-months treatment [ECCO Abstract P452. Presented at: 11th Congress of ECCO, March 19-19, 2016, Amsterdam, Netherlands.

43. Guerra Veloz MF, Belvis Jimenez M, Vazquez Moron JM, et al. Switching reference infliximab to CT-P13 in patients with inflammatory bowel disease: Multicentre study at 12 months results [ECCO Abstract P519]. Presented at: 13th Congress of ECCO, February 14-17, 2018, Vienna, Austria.

44. Guidi L, Fiorino G, Variola A, et al. The PROSIT cohort of infliximab biosimilar in IBD: A prolonged follow-up on the efficacy and safety across Italy [ECCO Abstract OP005]. Presented at: 12th Congress of ECCO, February 15-18, 2017, Barcelona, Spain.

45. Hamanaka S, Nakagawa $\mathrm{T}$, Koseki H, et al. Infliximab biosimilar in the treatment of inflammatory bowel disease: a Japanese single-cohort observational study [ECCO Abstract P329]. Presented 
at: 11th Congress of ECCO, March 16-19, 2016, Amsterdam, Netherlands.

46. Hlavaty T, Krajcovicova A, Sturdik J, et al. Biosimilar infliximab CT-P13 treatment in patients with inflammatory bowel diseases: a 1-year, single-centre retrospective study [ECCO Abstract P655]. Presented at: 11th Congress of ECCO, March 16-19, 2016, Amsterdam, Netherlands.

47. Hoivic ML, Buer LC, Bolstad N, et al. Switching from originator to biosimilar infliximab - real-world data from 18 months prospective follow-up of a single-centre IBD population [ECCO Abstract P705]. Presented at: 13th Congress of ECCO, February 14-17, 2018, Vienna, Austria.

48. Huoponen S, Eberl A, Rasanen P, et al. Switching from originatorinfliximab to biosimilar infliximab has no influence on health-related quality of life and clinical disease activity among patients with inflammatory bowel disease [ECCO Abstract P685]. Presented at: 12th Congress of ECCO, February 15-18, 2017, Barcelona, Spain.

49. Ilias A, Szanto K, Gonczi L, et al. Non-medical mandatory reversed and back and forth switch between infliximab and its biosimilar: Early clinical outcomes [ECCO Abstract P694]. Presented at: 13th Congress of ECCO, February 14-17, 2018, Vienna, Austria.

50. Kierkus J. Preliminary assessment of efficacy and safety of switching between originator and biosimilar infliximab in paediatric Crohn Disease patients. [DDW Abstract Tu1081]. Presented at: Digestive Disease Week Annual Meeting, May 17-19, 2015, Washington, DC.

51. Nugent $\mathrm{S}$ ea. EirSwitch echoes of NorSwitch: Switching biosimilar therapy in an IBD cohort an Irish experience [ECCO Abstract P430]. Presented at: 12th Congress of ECCO, February 15-18, 2017, Barcelona, Spain.

52. Petitdidier N, Gagniere C, Rentien AL, et al. Patients' perspectives on switching from reference infliximab to CT-P13 biosimilar in patients with inflammatory bowel disease: a 12-month prospective observational cohort study [ECCO Abstract P528]. Presented at: 13th Congress of ECCO, February 14-17, 2018, Vienna, Austria.

53. Pierik MJ, van der Meulen-de Jong AE, Bloemstaat-Minekus JPJ, et al. Switching from the originator infliximab to biosimilar CT-P13 did not change the quality of life and clinical efficacy for IBD patients in stable remission in daily clinical practice (interim analysis) [ECCO Abstract P464]. Presented at: 13th Congress of ECCO, February 14-17, 2018, Vienna Austria.

54. Rodriguez Glez GE, Diaz Hernandez L, Morales Barrios JA, et al. Efficacy, safety and economic impact of the switch to biosimilar of infliximab in inflammatory bowel disease patients in clinical practice: results of one year [ECCO Abstract P629]. Presented at: 12th Congress of ECCO, February 15-18, 2017, Barcelona, Spain.

55. Sieczkowska J, Jarzebicka D, Oracz G, et al. Immunogenicity after switching from reference infliximab to biosimilar in children with Crohn's [ECCO Abstract P617]. Presented at: 11th Congress of ECCO, March 19-19, 2016, Amsterdam, Netherlands.

56. Sladek M, Vultaggio A, Ghione S, et al. Comparable clinical efficacy, safety and immunogenicity of infliximab biosimilar (CT-P13) after transition from reference infliximab (Remicade ${ }^{\circledR}$ ) in children with established inflammatory bowel disease: a multi-centre prospective observational [ECCO Abstract P661]. Presented at: 12th Congress of ECCO, February 15-18, 2017, Barcelona, Spain.

57. Smits LJ, Derikx L, van Esch AA, et al. Drug survival and immunogenicity after switching from Remicade ${ }^{\circledR}$ to biosimilar CT-P13 in inflammatory bowel disease patients: two-year follow-up of a prospective observational cohort study [ECCO Abstract P490]. Presented at: 13th Congress of ECCO, February 14-17, 2018, Vienna, Austria.

58. Suk JY, Park DI, Kim YH, et al. Efficacy and safety of infliximab's biosimilar (REMSIMA) for IBD [ECCO abstract P540]. Presented at: 10th Congress of ECCO, February 18-21, 2015; Barcelona, Spain.
59. Cohen HP, Blauvelt A, Rifkin RM, Danese S, Gokhale SB, Woollett G. Switching reference medicines to biosimilar: a systematic literature review of clinical outcomes. Drugs. 2018;78:463-478.

60. Gisbert JP, Chaparro M. Switching from and originator anti-TNF to a biosimiar in patients with inflammatory bowel disease: can it be recommended? A systematic review. Gastroenterol Hepatol. 2018;41:389-409.

61. Faegan BG, Lam G, Ma C, Lichtenstein GR. Systematic review: efficacy and safety of switching patients between reference and biosimilar infliximab. Aliment Pharmacol Ther. 2019;49:31-40.

62. Komaki Y, Yamada A, Komaki F, Micic D, Ido A, Sakuraba A. Systematic review with meta-analysis: the efficacy and safety of CT-P13, a biosimilar of anti-tumour necrosis factor-alpha agent (infliximab), in inflammatory bowel diseases. Aliment Pharmacol Ther. 2017;45:1043-1057.

63. Radin M, Sciascia S, Roccatello D, Cuadrado MJ. Infliximab biosimilars in the treatment of inflammatory bowel diseases: a systematic review. BioDrugs. 2017;31:37-49.

64. Faccin F, Tebbey P, Alexander E, Wang X, Cui L, Albuquerque T. The design of clinical trials to support the switching and alternation of biosimilars. Expert Opin Biol Ther. 2016;16:1445-1453.

65. Ben-Horin S, Yavzori M, Benhar I, et al. Cross-immunogenicity: antibodies to infliximab in Remicade-treated patients with IBD similarly recognise the biosimilar Remsima. Gut. 2016;65:1132-1138.

66. Humira Product Monograph. North Chicago: Abbvie Corporation; 2017.

67. Simponi Product Monograph. Beerse: Janssen Inc.; 2014

68. Cimzia Product Monograph. Oakville: UCB Canada Inc.; 2014.

69. Enbrel Product Monograph. Mississauga: Amgen Canada Inc.; 2015.

70. Guideline on immunogenicity assessment of monoclonal antibodies intended for in vivo clinical use. European Medicines Agency; May 2012.

71. Scott BJ, Klein AV, Wang J. Biosimilar monoclonal antibodies: A Canadian regulatory perspective on the assessment of clinically relevant differences and indication extrapolation. J Clin Pharmacol. 2015;55:S123-S132.

72. Mould DR. The pharmacokinetics of biologics: a primer. Dig Dis. 2015;33:61-69.

73. Ben-Horin S, Vande Casteele N, Schreiber S, Lakatos PL. Biosimilars in Inflammatory bowel disease: facts and fears of extrapolation. Clin Gastroenterol Hepatol. 2016;14:1685-1696.

74. Gonczi L, Vegh Z, Golovics PA, et al. Prediction of short- and medium-term efficacy of biosimilar infliximab therapy Do trough levels and antidrug antibody levels or clinical and biochemical markers play the more important role? J Crohns Colitis. 2017;11:697-705.

75. Gecse KB, Vegh Z, Kurti Z, et al. Final results on efficacy and safety of biosimilar infliximab after one-year: results from a prospective nationwide cohort [ECCO abstract P331]. Presented at: 12th Congress of ECCO, February 15-18, 2017, Barcelona, Spain 2017.

76. Lovasz BD, Kurti Z, Rutka M, et al. Final results on immunogenicity profile and predictors of ADA development of biosimilar infliximab during the first 12 months of the therapy: results from a prospective nationwide cohort [ECCO abstract P592]. Presented at: 12th Congress of ECCO, February 15-18, 2017, Barcelona, Spain 2017.

77. US Food and Drug Administration. FDA Guidance Documents: Considerations in demonstrating interchangeability with a reference product. https://www.fda.gov/regulatory-information/searc h-fda-guidance-documents/considerations-demonstrating-interchang eability-reference-product-guidance-industry; 2019.

Publisher's Note Springer Nature remains neutral with regard to jurisdictional claims in published maps and institutional affiliations. 